\title{
What Determines Tax Evasion Attitude: A Study in Selected Zones of SNNPR, Ethiopia
}

\author{
Yonas Sendaba $^{1}$, Tsegazeab Teklemariam ${ }^{1}$, Daniel Balcha $^{1}$, Samson Wondimu $^{1}$, Tariku Lorato ${ }^{2}$ \\ ${ }^{1}$ Department of Accounting and Finance, Dilla University, Dilla, Ethiopia \\ ${ }^{2}$ Department of Economics, Dilla University, Dilla, Ethiopia
}

Email address:

yon2002@gmail.com (Y. Sendaba), tsegadu05@gmail.com (T. Teklemariam), danielbalcha02@gmail.com (D. Balcha),

Samvod1249@gmail.com (S. Wondimu),tarikulorato@gmail.com (T. Lorato)

\section{To cite this article:}

Yonas Sendaba, Tsegazeab Teklemariam, Daniel Balcha, Samson Wondimu, Tariku Lorato. What Determines Tax Evasion Attitude: A Study in Selected Zones of SNNPR, Ethiopia. Journal of Finance and Accounting. Vol. 9, No. 4, 2021, pp. 117-126.

doi: $10.11648 /$ j.jfa.20210904.12

Received: May 28, 2021; Accepted: July 6, 2021; Published: July 13, 2021

\begin{abstract}
Tax evasion is a phenomenon in every nation even if the magnitude and causes may vary. It is associated with the introduction of taxation itself; tax evasion is a serious problem to a tax system. Therefore, examining what contributes to evasion in a given tax system is vital so that the negative consequences might be identified and solved. The study sought to identifies determinant factors of taxes evasion attitude of taxpayers in selected five zones: Gedeo, Gamo, Hadiya, Halaba and Gurage zone of Southern Nations, Nationalities and Peoples Regions (SNNPR) Ethiopia. Using Yamane (1967) formula and sampled 956 respondents. We have categorized our respondents as evaders, non-evaders and neutral based on the average value of their response and exclude neutral respondents. Accordingly, we used 768 questionnaires. We used a logistic regression model to examine what determines the evasion attitude of taxpayers. It is identified that significant difference among taxpayers towards tax evasion at zone level; Category A taxpayers are inclined to evasion compared to B; the level of education, peer, tax rate, and tax system has contributed to tax evasion attitude positively; and Authorized accountants are found to be facilitators for evasion. Based on our result we concluded that system orients variables are the most determinant factors affecting the evasion attitude of taxpayers compared to demographic attributes.
\end{abstract}

Keywords: Tax Evasion Attitude, Determinants, Logistic Regression Model, SNNPR, Ethiopia

\section{Introduction}

The evolution of tax evasion is associated with the introduction of taxation [1]. Tax evasion is a global scenario irrespective of any attribute of a country [2, 3] and has been experienced in both developed as well as developing countries. Unless nations are able to mitigate and minimize magnitude of tax evasion, it will be difficult to overcome illicit financial activities \& cash flows and drain channels of corruption [4]

Tax evasion includes all unlawful activities by a taxpayer with the motive of minimizing tax liability. It occurs when taxpayers intentionally failed to execute their tax responsibility. It is an intentional violation of laws and it is evident in situations where tax liability is fraudulently reduced, or false claims are filled on the revenue tax form.

The definition of tax evasion can be seen with two sides.
The first concept is total with the underlying of tax evasion is presented with any form of the business. In this scenario; "tax evasion can be defined as the activity in which they badly behaved and premeditated violation of law to escape tax payments that have been indisputably inflicted by the tax authority" [5]. On the other side, scholars are associated tax evasion with the informality. In this concept; tax evasion can be defined as "an activity commonly associated with the informal economy. One measure of the extent of tax evasion is the amount of unreported income, which is the difference between the amounts of income that should be reported to the tax authorities and the actual amount reported" [6].

United States Internal Revenue Service (IRS) defined Tax evasion as "an intentional misrepresentation of material facts, performed by the taxpayer with the specific purpose of evading a tax p or believed to be owed" [7].

In recent years, developing countries' tax losses from 
aggressive tax planning and avoidance by multinational companies is sizable Profit shifting by multinational corporations through transfer mispricing. Recent estimates suggest that losses could be between USD 100 to 240 billion annually in global corporate income tax revenue [8].

Examining the tax revenue collection trend of SNNPR, exhibited a significant and increasing margin between the planned and actual revenue collection. As it is depicted in figure 1 below, all the periods we have examined, there is a departure of actual total tax revenue collection from the planned one. Moreover, the gap is increasing in recent years.

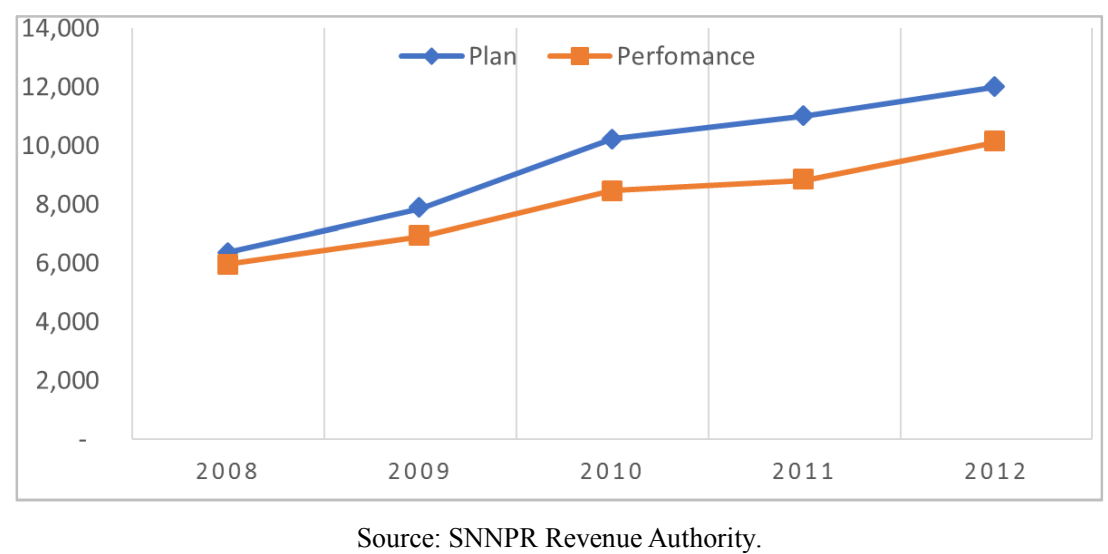

Figure 1. SNNPR Revenue Plan vs Performance.

A study by Kiri [9] revealed that tax rate, audit probability, and penalty rate are factors that influence tax evasion. factors that generally determine tax evasion level in a country categorized in to three 1) traditional (tax rate, penalty rate and audit probability), 2) institutional (corruption, cost compliance, and confidence), 3) socio-cultural (age, sex, education, social rules etc.) [10].

Yalama, Gamze; \& Gumus, [11] examined determinants of tax evasion form institutional perspectives, and identified that the system complexity and detection probability had a significant bearing on tax evasion.

Individual factors were; age, gender, marital status, level of education, level and source of income, and compliant peers. The factors related to the Inland Revenue authority service were; marginal tax rate, detection, penalties and tax administration. The psychological factors; religion, being risk-averse or risklovers, feeling towards government and tax morale.

Comparing which factor is more dominant, the source of income is found to be an important factor in both developed and developing countries [12]. Discontent with the government, caused by the feeling towards how government spend their tax, combined with low detection probability are among the biggest influencing factors, and served as a rationalization to evade tax [13].

Accountancy firms may simplify tax evasion for evasionprone taxpayers by indicating the loopholes emanated from the complex nature of tax laws [14]. "The strategies and tactics used by accountancy firms to sell schemes that enable their clients to avoid corporate, sales and payroll taxes. Such strategies stimulate reflections upon the possible trajectories in the development of accountancy firms and social consequences of their trade" [15].

Amina and Saniya [16] examined determinants of tax compliance and age, gender, penalty, audit frequency, and the perceived role of government are found to affect compliance tendency of taxpayers. Endashaw [17], has identified tax rate, income level, detection probability, penalty rate, the complexity of tax system, perceived role of government, peer influence on tax evasion, age, gender and education factors are found to be statistically significant

Empirical evidence of the above studies shows that many institutional, systematic, and behavioral factors are contributing factors for cultivating the positive attitude towards tax evasion in different nations, no exception will be for Ethiopia. Thus, this research is aimed at investigating the most influential determining factor of tax evasion attitude in the Ethiopian with particular emphasis on selected zones of SNNPR.

The previous researchers $[16,17]$ studied the tax system, the tax rate, the probability of audit, and other pushing factors toward tax evasion mostly in category A, but not in category B. Thus, category B is not addressed in the study area even if it has a great impact on the tax revenue. Those above-mentioned researchers also not addressed the role of public accountants in the facilitating of tax evasion in Ethiopian tax history. The other gap we have identified in the study area coverage, to the knowledge of the researchers, previous studies usually over a very limited area of study such as a city or sub-city of a single category of taxpayers. Thus, the current research fills the gap identified related to category $\mathrm{A}$ and $\mathrm{B}$ at the regional level by selecting five zones as per their significant share of the number of taxpayers

Even if taxes evasion is the burning issue, the researchers believed that it is an under-examined issue and we believed that the causes need to be investigated thoroughly with a wider geographic scope. The other issue that needs to be bridged by research is that most of the researchers rely on VAT, but we have tried to investigate the evasion attitude on the overall tax duty.

The major objective of this study is to identify determinant 
factors of taxes evasion attitude in the selected zones of SNNPR Ethiopia.

This research would pave the way for effective policy formulation and implementation to minimize tax evasion and enhance compliance since it may enable the government to work on the determinants of evasion attitude.

It is rarely possible to cover all geographic areas or jurisdictions with single research, therefore, the researchers limited the scope of this study on determinant factors contributing to evasion attitude of taxpayers based on the survey made in selected zones of SNNPR category "A" and "B" Taxpayers.

The conceptual framework is designed after a detailed review of related literature and considering the variables.

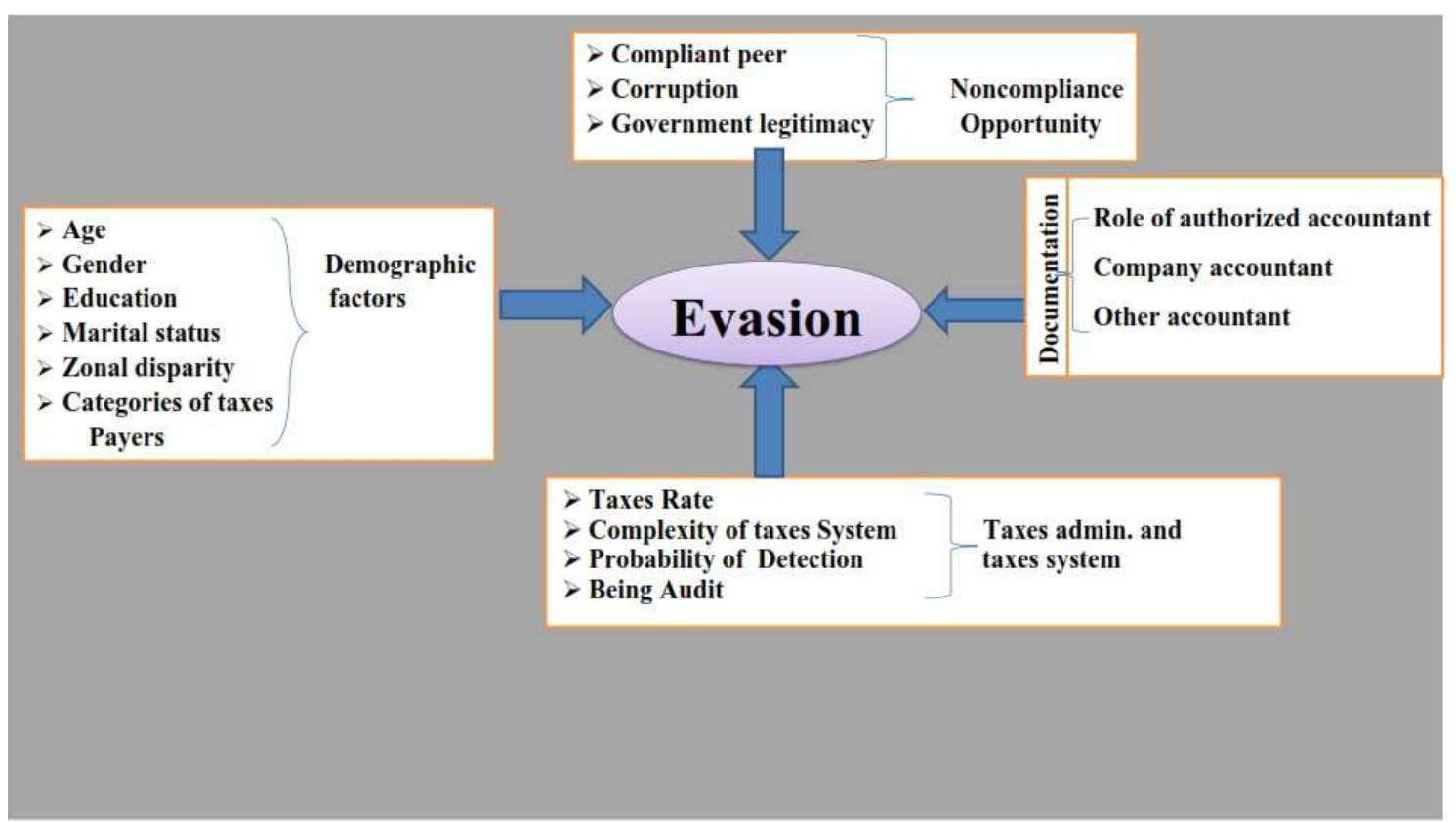

Source: Researchers' own design.

Figure 2. Conceptual Framework.

\section{Research Methodology}

\subsection{Description of the Study Area}

Southern Nation Nationalities and Peoples Region (SNNPR) is among the ten regional states in Ethiopia, which accounts for more than $10 \%$ of the country's coverage area. Based on CSA [18] projection on the basis of 2007 census, the SNNPR region has an estimated population size of 20,087,000.

\subsection{Research Design}

Research design is a blue print for a research. It embraces the connection of philosophy, strategies of inquiry and specific methods. Explanatory research, which is used for our study, tries to establish the association among variables. this research aimed to identify how one variable affects the other; it seeks to provide an empirical explanation for the causal relationship between one or more variable [19].

\subsection{Research Approach}

Determining the most appropriate research approach should consider various aspects, such as research questions, objectives, and the issue to be investigated. Mixed research approach uses both quantitative and qualitative [20]. Since we have collected and used both qualitative and quantitative data, this study has employed a mixed research approach to address the research objectives.

\subsection{Target Population}

Targeted populations of this study were category 'A' and 'B' business income taxpayers and tax officials of revenue offices registered in the selected Zones. These are targeted as they are required by law to maintain and submit books of accounts to the tax authority within the stipulated time and have higher annual turnover and the tax officials were selected as they have the knowledge and exposure to tax evasion.

\subsection{Sampling Techniques}

Different sampling techniques were used for those different parties involved as respondents of the research. A multi-stage area sampling procedure was used to select study Zones. From the total of ten regional states found in Ethiopia, the researchers selected purposively SNNPR. And from total fourteen zones found in SNNPR, four zones (Gamo, Hadiya, Gurage and Gedeo) were selected based on the highest number of business income taxpayers and the remaining one Halaba zone (as of its recent restructuring from specialworeda to zone in 2018) was selected purposively to look at how the evasion attitude is at the new zone level. From each 
zone, two cities (Zones capital city and nearby Woreda) were selected considering the concentration of large numbers of business income taxpayers. Then simple random sampling technic is used to select taxpayers from each category "A" and "B". From each revenue office found in five zones tax, compliance and law enforcement departments were selected purposively.

\subsection{Sample Size}

We have computed the sample size as per the data obtained from the regional revenue authority regarding the number of taxpayers which is presented in the table below with the alpha degree of 0.10 precision level. Tolerable level of sampling error which a researcher is willing to accept is avital component of a decision to be made regarding sample size [21]. To determine the sample size from each Zone, Yamane [22] formula $n=N /(1+N(e 2)$ was used by taking into account the total taxpayers, and $10 \%$ sampling error for each category. The researchers distributed a total of 956 questionnaires maintaining a $10 \%$ margin of safety.

Tax officials: from each sampled zone tax law enforcement department, the researchers have selected the directors for the law enforcement Department for each of the studied Zones. Since they are involved in evasion mitigation and compliance enhancement which results in having a better knowledge understanding of the issue.

\subsection{Data: Type, Source and Collection Instruments}

Both primary and secondary data sources were used in this study. Primary data were collected form the taxpayers through structured questioner and tax officials through interview. The questioner was distributed and collected by trained enumerators selected from the Tax Education \& Support Directorate of the revenue office under researchers' intact supervisions and the interview with respective tax officials was made by researchers. Correspondingly, the data acquired from primary sources for this study were collected through a self-administered questionnaire prepared using a five-point Likert scale ranging from strongly disagree, to strongly agree.

Secondary data were obtained from SNNPR Revenue Authority, and form various published and unpublished reports and publications.

\subsection{Method of Data Analysis}

Diverse data analysis methods were used depending on the objective of the study and the nature of the data collected. Data processing \& analyzing software package for social science version 20 and Stata version 12 were used to process and analyze data obtained from the structured questionnaire. Interview results were merged with the results in narrative.

\subsection{Model Specification and Estimation Procedures}

In this study the dependent variable is tax evasion attitude; whether the respondents have a positive attitude towards tax evasion or not is a binary type variable model, which is dichotomous or dummy variable regression model. Kumar,
[23] noted that "any score can be assigned as long as the intensity of the response pattern is reflected in the score and the highest score is assigned to the response with the highest intensity." The study has used judgment to categorize range of scores computed on the five points Likert scale as follows: a mean score of above 3.25 have taken as agree/ strongly agree, a mean score of 2.75 up to 3.25 as neutral and a mean score below 2.75 as strongly disagree/disagree on the Likert scale. Then the neutral value is dropped out from the analysis and the researcher assigned the value 1 for a positive attitude towards tax evasion i.e. agree/ strongly agree on for the mean value above 3.25 and 0 otherwise i.e strongly disagree/disagree for the mean value below $2 . .75$ on the five points Likert scale

For the analysis of dichotomous outcomes variable, a logistic regression model is appropriate over others Leeshawn \& Hosmer [24] in that it is an very flexible and easily usable mathematical model the provides results in a expressive interpretation. Thus; this study employed logistic regression model to examine the determinants of tax evasion attitude in the selected zone of SNNPR, Ethiopia. The analysis of the model illustrate that a change of an independent variable changes the probability that a given respondent's attitude towards tax evasion and it helps to predict the probability of tax evasion. Based on Gujarati, [25] and Lemeshow \& Hosmer [24] the functional form of logistic model is specified as follows:

$$
\mathrm{Pi}=\mathrm{EY}=1 / \mathrm{Xi}=11+\mathrm{e}-(\beta 0+\beta \mathrm{iXi})
$$

For ease of exposition, we write (5) as

$$
\mathrm{Pi}=11+\mathrm{e}-\mathrm{Zi}
$$

The probability that a given positive attitude of respondents for tax evasion expressed by (2) while, the probability of negative attitude is:-

$$
1-\mathrm{Pi}=11+\mathrm{eZi}
$$

Therefore, we can write:

$$
\mathrm{Pi} 1-\mathrm{Pi}=1+\mathrm{eZi} 1+\mathrm{e}-\mathrm{Zi}
$$

Now, (Pi/1-Pi) is simply the odds ratio in favour of a positive tax attitude. The ratio of the probability that the positive attitude of respondents for tax evasion to the probability of that it will not have a positive attitude. Finally, taking the natural log of equation (4) we obtain:-

$$
\mathrm{Li}=\operatorname{lnPi} 1-\mathrm{Pi}=\beta \mathrm{o}+\beta 1 \mathrm{X} 1+\beta 2 \mathrm{X} 2+\ldots+\beta \mathrm{nXn}+\mathrm{Ui}
$$

Where $\mathrm{Pi}=$ is a probability of positive attitude towards tax evasion ranges from 0 to 1

$\mathrm{Zi}=$ is a function of $\mathrm{n}$ explanatory variables $(\mathrm{X})$ which is also expressed as:-

$$
\mathrm{Zi}=\beta \mathrm{o}+\beta 1 \mathrm{X} 1+\beta 2 \mathrm{X} 2+\ldots+\beta \mathrm{nXn}+\mathrm{Ui}
$$

$\beta$ o is an intercept

$\beta 1, \beta 2 \ldots \ldots \beta$ are slopes of the equation in the model 
$\mathrm{Li}=\mathrm{is} \log$ of the odds ratio, which is linear in $\mathrm{Xi}$

$\mathrm{Xi}=$ is vector of relevant taxpayers' characteristics

$\mathrm{Ui}=$ is the disturbance term of the logit model
Therefore, for this study, the binary logistic regression is written as follows:

$$
\begin{gathered}
\mathrm{Zi}=\beta \mathrm{o}+\beta 1 \text { zone }+\beta 2 \text { Category }+\beta 3 \text { Gender }+\beta 4 \text { Age }+\beta 5 \text { Education } \\
+\beta 6 \text { legtimacy }+\beta 7 \text { corruption }+\beta \text { rate }+\beta 9 \text { system }+\beta 10 \text { detection }+\beta 11 \text { pact }+\beta 12 \text { peer }+ \text { Ui }
\end{gathered}
$$

For details of variables and their measurement (see Table 1)

Table 1. Lists of variables and their measurement.

\begin{tabular}{llc}
\hline Symbol & Variable description & Measurement \\
\hline Att & Attitude of tax payers toward tax evasion & Nominal \\
Gender & Gender of Respondent/ Taxpayer & Nominal \\
Zone & Zonal residency of Taxpayer & Nominal \\
Education & Educational Background of Taxpayers & Ordinal \\
Category & Category of Taxpayers & Ordinal \\
legtimacy & Impact of Government Legitimacy on tax evasion Attitude & Scale \\
corruption & Impact of Tax officers' corrupt behaviour on Evasion Attitude & Scale \\
rate & Effect of tax rate on evasion attitude & Scale \\
system & Impact of tax system on evasion attitude & Independent \\
detection & Impact of detection possibility on evasion attitude & \\
pacct & The role of public accountant on evasion & \\
SRM & Effect of SRM on Evasion attitude & Nominal \\
Audit & Whether the organization has been audited by revenue authority before & Scale \\
Documentation & Who prepares tax returns of the organization for tax filing & \\
Penalty & effect of penalty on evasion attitude & \\
\hline
\end{tabular}

Source: Survey 2020 and Own Computation.

\subsection{Reliability and Validity Tests}

\subsubsection{Reliability Test}

Reliability measures the items stability, consistency, or dependability in questionnaire. In this research, Cronbach's alpha has been used to test the reliability of the items included in the questionnaire. As it was depicted in table 2 below the overall Cronbach's Alpha of the seven variables computed to be above 0.7 which indicates very good reliability. The result of three variables is found to be lower than 0.7, but Pallant [26] (p. 85) argued that if the number of items is less than 10 (ten) the Cronbach's Alpha value should be greater than 0.5 which is also the case satisfied in our study. Therefore, the results obtained reveal that the questionnaire used in this study has justified reliability.

Table 2. Reliability Statistics.

\begin{tabular}{lll}
\hline Scale Variable & Cronbach's Alpha & No. of Items \\
\hline Attitude & 0.772 & 8 \\
Government Legitimacy & 0.991 & 11 \\
Corruption & 0.868 & 7 \\
Peer influence & 0.989 & 5 \\
Tax Rate & 0.845 & 7 \\
Sales Register Machine & 0.760 & 7 \\
Authorize Accountant Role & 0.753 & 7 \\
Tax System & 0.681 & 9 \\
Detection & 0.615 & 6 \\
Penalty & 0.603 & 5 \\
\hline
\end{tabular}

Source: Survey 2020 and Own Computation.

\subsubsection{Validity Test}

To check the validity of the questionnaire being used in this study, a pilot test was conducted with some category A and $\mathrm{B}$ business income taxpayers from Gedeo zone. The questionnaire was also assessed for content validity and terminology by the tax official from the SNNPR revenue tax office. After the pilot test and after the tax officials content assessment had been carried out, necessary modifications or amendments on some items and complete removal and replacement of unclear questions were done.

\section{Discussion}

\subsection{Response Rate}

The response rate measures how effective the instrument distribution and collection were; to have a higher rate of response rate imply the data collection procedure is well managed. In our case, we adopted various practical strategies and tactics to collect data.

We were able to manage the smooth flow of data collection by creating consensus on the positive contribution and relevance of the research result, by creating clarity on the contents and intentions of the questions included and variables to be measured in the questionnaires; giving induction to data enumerators to enhance their communication skill, and having a participatory instrument distribution. The overall response rate is computed to $80.25 \%$; for survey research, a response rate of $\geq 80 \%$ is expected [27].

Therefore, this figure satisfies the minimum requirement. We have considered those usable questionnaires only to compute the response rate since "it is considered as a matter of academic integrity to state clearly and refer to the numbers and percentage of usable questionnaires" [28]. 
Table 3. Logistic model for attitude, goodness-of-fit test (Table collapsed on quantiles of estimated probabilities).

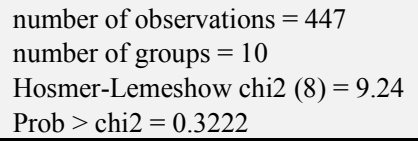

Source: Survey 2020 and Own Computation.

Table 4. The estimates of binary logistic model and the effects of explanatory variables on the tax evasion attitude on selected variables.

\begin{tabular}{|c|c|c|c|c|c|}
\hline Att & Coef. & Odds ratio & Std. Err. & $\mathbf{Z}$ & $\mathbf{P}>\mathbf{Z}$ \\
\hline \multicolumn{6}{|l|}{ Zone } \\
\hline Gedeo & .4894224 & 1.631374 & .462805 & 1.06 & 0.290 \\
\hline Hadiya & 1.676142 & 5.344895 & .388551 & 4.31 & $0.000 * * *$ \\
\hline Halaba & 1.049937 & 2.857471 & .4934559 & 2.13 & $0.033 * *$ \\
\hline Gurage & 1.31927 & 3.740689 & .5007616 & 2.63 & $0.008^{* * *}$ \\
\hline Category & .522943 & 1.686985 & .2588309 & 2.02 & $0.043 * *$ \\
\hline Gender & .000621 & 1.000621 & .3138249 & 0.00 & 0.998 \\
\hline \multicolumn{6}{|l|}{ Age } \\
\hline $30-45$ & .4527355 & 1.572608 & .3247074 & 1.39 & 0.163 \\
\hline$>45$ & .6314502 & 1.880336 & .5229219 & 1.21 & 0.227 \\
\hline \multicolumn{6}{|l|}{ Marital status } \\
\hline Married & -.2075627 & .8125623 & .3126206 & -0.66 & 0.507 \\
\hline Divorced & -.4755391 & .6215499 & .8965446 & -0.53 & 0.596 \\
\hline Widowed & -.2695383 & .7637321 & 1.177236 & -0.23 & 0.819 \\
\hline \multicolumn{6}{|l|}{ Education } \\
\hline Primary Edu com’t & 1.166203 & 3.209781 & .5978299 & 1.95 & $0.051 *$ \\
\hline Secondary Edu com’t & .5067972 & 1.659966 & .5299123 & 0.96 & 0.339 \\
\hline Diploma & .5193851 & 1.680994 & .5528596 & 0.94 & 0.347 \\
\hline Degree and above & -.0191619 & .9810205 & .6007682 & -0.03 & 0.975 \\
\hline Legitimacy & -.2369618 & .7890214 & .2185829 & -1.08 & 0.278 \\
\hline Peer & .829082 & 2.291215 & .2473903 & 3.35 & $0.001^{* * *}$ \\
\hline corruption & -.103602 & .9015841 & .1783778 & -0.58 & 0.561 \\
\hline Rate & .5427445 & 1.720723 & .198009 & 2.74 & $0.006 * * *$ \\
\hline System & .8500041 & 2.339657 & .2938653 & 2.89 & $0.004 * * *$ \\
\hline Detection & .3032006 & 1.354186 & .2356117 & 1.29 & 0.198 \\
\hline Audit & .1913592 & 1.210894 & .2906279 & 0.66 & 0.510 \\
\hline Documentation & & & & & 0.518 \\
\hline Company accountant & -.763988 & .4658051 & 1.180741 & -0.65 & 0.195 \\
\hline Others & .6489435 & 1.913518 & .5005745 & 1.30 & 0.233 \\
\hline Pact & .0142993 & 1.014402 & .0119785 & 1.19 & $0.000^{* * *}$ \\
\hline \multirow{5}{*}{ cons } & -9.914903 & .0000494 & & -6.54 & 0.000 \\
\hline & \multicolumn{5}{|c|}{ Logistic regression Number of obs $=442$} \\
\hline & \multicolumn{5}{|c|}{ Wald chi2 $(25)=95.30$} \\
\hline & \multicolumn{5}{|c|}{ Prob $>$ chi $2=0.0000$} \\
\hline & \multicolumn{5}{|c|}{ Log pseudolikelihood $=-210.51761$ Pseudo $R 2=0.2664$} \\
\hline
\end{tabular}

Source: Own survey data computation, (2020).

The asterisks $* * *$, and ${ }^{* *}$ indicate $1 \%$, and $5 \%$ significance level, respectively.

\subsection{Determinants of Evasion Attitude}

Based on the value label to each explanatory variable logistic regression was used to identify the possible effects of the explanatory variables on the attitudes of tax evasion which is identified as 1 if the respondent has a positive attitude towards tax evasion, 0 otherwise.

The STATA provides regression output for the dependent variable attitude of tax evasion of respondent's terms of the corresponding explanatory variables for the 768 sample observations/respondents. The hypothesized variables were tested for the existence of multicollinearity tests.

\subsection{Test for Multi Co Linearity and Correlation Analysis}

In most economic variables a set of independent variables within themselves likely correlated each other. In situations where there is significant collinearity among the independent variables, there is difficulty in differentiating which variable should be in the interest of the study. Collinearity ranges from 1 where there is the complete relationship within the independent variables to 0 where there is no relationship at all [11]. Therefore, before proceeding to analyze the causal relationship among variables, they were checked for prevalence of multicollinearity using a correlation matrix table (see Table 5). To check for multicollinearity, which occurs when there is a strong correlation between two or more predictor variables in a regression model. The results of our study, from the correlation matrix testified the highest correlation coefficient of 0.502 ; signifying the nonexistence of multicollinearity problem. 
We employed correlation analysis to scrutinize the association between the dependent and independent variables of the study. The Cohen's (1998) guideline, $r=0.10$ to 0.29 for a weak correlation, $r=0.30$ to 0.49 for a moderate correlation, $\mathrm{r}=0.50$ to 1.0 for a strong correlation was adopted for interpreting the result of the analysis. By using correlation analysis, the findings of the study show that government legitimacy has a weak and negative correlation with tax evasion attitude $(r=-0.015)$, Peer influence showed a moderate and significant positive correlation with tax evasion attitude $(\mathrm{r}=0.367)$; Corruption exhibited a weak and positive correlation with tax evasion attitude $(\mathrm{r}=0.055)$; tax rate and tax system exhibited a moderate and positive correlation with tax evasion attitude $(\mathrm{r}=0.297)$ and $(\mathrm{r}=0.300)$ respectively; Audit $(\mathrm{r}=0.067)$, Detection $(\mathrm{r}=0.163)$, SRM $(\mathrm{r}=0.166)$ and role of public accountant $(\mathrm{r}=0.273)$ have a weak and positive correlation with tax evasion attitude; Gender $(\mathrm{r}=-0.067)$; Age $(\mathrm{r}=0.131)$; Marital states $(\mathrm{r}=-0.033)$ and Education $(\mathrm{r}=$ 0.121 ) a weak and negative. There is no significant correlation between government legitimacy, audit, corruption, gender, marital status, and tax evasion but the relationship is negative for government legitimacy, gender and marital status; positive for audit and corruption. (See Table 6)

Table 5. Multicollinearity Test Result.

\begin{tabular}{|c|c|c|c|c|c|c|c|c|c|c|c|c|c|}
\hline & Cate. & Gen. & Age & Marit & Edu. & Legit. & Peer & Corrupti & Tax rate & Taxsyst & Audit & Detec. & Pub. Acct \\
\hline Category & 1 & .042 & -.045 & .024 & $-.115^{* *}$ & -.060 & -.031 & -.044 & $-.088^{*}$ & -.055 & -.038 & .005 & -.026 \\
\hline Geneder & .042 & 1 & $-.090^{*}$ & $.142^{* *}$ & .035 & .065 & .004 & -.022 & $-.124^{* *}$ & .016 & -.041 & .063 & .044 \\
\hline Age & -.045 & $-.090^{*}$ & 1 & $.502^{* *}$ & $-.216^{* *}$ & -.039 & -.033 & .024 & $.077^{*}$ & $-.112^{* *}$ & $-.183^{* *}$ & $-.092^{*}$ & $-.112^{* *}$ \\
\hline Education & $-.115^{* *}$ & .035 & $-.216^{* *}$ & $-.179^{* *}$ & 1 & -.010 & .038 & -.031 & $-.131^{* *}$ & $.095^{* *}$ & $.111^{*}$ & .059 & .060 \\
\hline Legitimacy & -.060 & .065 & -.039 & -.002 & -.010 & 1 & $.139^{* *}$ & $.077^{*}$ & -.011 & $.348^{* *}$ & .057 & $.274^{* *}$ & $.213^{* *}$ \\
\hline Peer & -.031 & .004 & -.033 & -.048 & .038 & $.139^{* *}$ & 1 & $.256^{* *}$ & $.275^{* *}$ & $.406^{* *}$ & .083 & $.393^{* *}$ & $.484^{* *}$ \\
\hline Tax rate & $-.088^{*}$ & $-.124^{* *}$ & $.077^{*}$ & .024 & $-.131^{* *}$ & -.011 & $.275^{* *}$ & $.345^{* *}$ & 1 & .037 & $-.092^{*}$ & .065 & $.109^{*}$ \\
\hline Tax system & -.055 & .016 & $-.112^{* *}$ & -.064 & $.095^{* *}$ & $.348^{* *}$ & $.406^{* *}$ & .006 & .037 & 1 & $.195^{* *}$ & $.469^{* *}$ & $.461^{* *}$ \\
\hline Audit & -.038 & -.041 & $-.183^{* *}$ & $-.135^{* *}$ & $.111^{*}$ & .057 & .083 & $-.099^{*}$ & $-.092^{*}$ & $.195^{* *}$ & 1 & $.273^{* *}$ & $.208^{* *}$ \\
\hline Detection & .005 & .063 & $-.092^{*}$ & -.025 & .059 & $.274^{* *}$ & $.393^{* *}$ & $.131^{* *}$ & .065 & $.469^{* *}$ & $.273^{* *}$ & 1 & $.523^{* *}$ \\
\hline SRM & $-.089^{*}$ & $.075^{*}$ & $-.095^{* *}$ & -.057 & .065 & $.324^{* *}$ & $.250^{* *}$ & -.061 & -.070 & $.453^{* *}$ & $.160^{* *}$ & $.439^{* *}$ & $.325^{* *}$ \\
\hline Public A & -.026 & .044 & $-.112^{* *}$ & $-.151^{* *}$ & .060 & $.213^{* *}$ & $.484^{* *}$ & .034 & $.109^{*}$ & $461^{\text {** }}$ & $.208^{* *}$ & $.523^{* *}$ & 1 \\
\hline
\end{tabular}

Source: survey 2020 and own computation.

Table 6. Correlation Result.

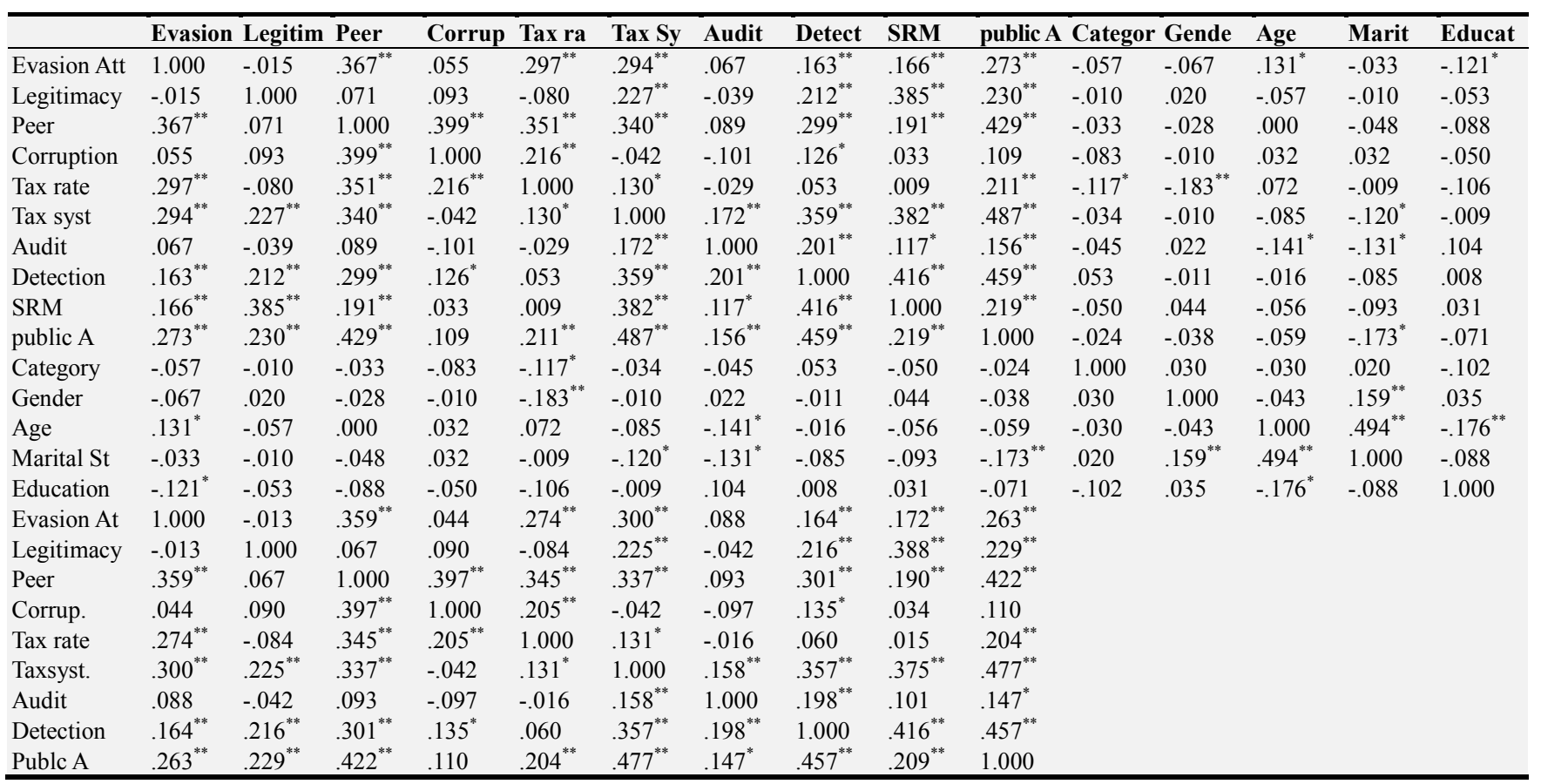

\subsection{Regression Result}

\subsubsection{The Goodness of Fit of the Model}

Correctly specified model can only lead as to draw a reliable conclusion and enable us to predict the future outcome based on our analysis. logistic regression is the most popular modelling approach for binary outcomes. Our data is manipulated to adhere assumptions made by the model. In this study, the Hosmer-Lemeshow [24] goodness of fit test is 
used to check the goodness of fit of the model.

\subsubsection{The Hosmer-Lemeshow Tests}

The Hosmer-Lemeshow tests are goodness of fit tests for ordinal logistic regression models. Basically, they compare observed frequencies with expected outcome and calculate a test statistic distributed in accordance with the chi-squared distribution [24]. The number of quantiles used \& outcome categories will determine the degrees of freedom. insignificant $p$-value shows that absence of evidence whether the observed and expected frequencies differ (i.e., evidence of good fit). If p-value is low (say, below 0.05), you reject the model. If it's high, then your model passes the test [29]. Therefore, the results of the model is insignificant (Prob $>$ chi2 $=0.3222$ ) shows evidence of good fit. (See Table 3 )

The logit model as a parameter estimates provide only the direction of the effect of explanatory variables, but the estimates neither stand for the actual size of change nor the probabilities [25]. However, the Odds of the model tell by what factor the dependent variable will change whenever a unit change occurs in the explanatory variable [30]. Thus, the result of logistic regression model and odds ratio explained as follows. (See Table 4)

Zone: As expected, the zone has a significant consequence on the tax evasion attitude. In our study Gamo zone is taken as a reference category based on the chi 2 result, tax evasion attitude of Gamo zone taxpayers is negative as compared to other zones. The model result also shows the significant difference among taxpayers' attitude towards tax evasion at the zone level. This variable is significant at $1 \%$ level of significance. The odds ratio results revealed that the odds in favor of tax evasion attitude increase by $5.344895 ; 2.857471$ and 3.740689 units respectively for Hadiya; Halaba; Gurage zones as compared to Gamo Zone. This implies that there is a positive attitude towards tax evasion in Hadiya; Halaba and Gurage zone taxpayers.

Category of taxpayers: The result revealed that there is a significant difference between category A and category B taxpayers towards tax evasion attitude. The odds ratio of 1.686985 shows that; if all other things are held constant, Category A taxpayers' attitude towards tax evasion increase by a factor of 1.686985 unit as compared to category B. This variable is significant at $5 \%$ level of significance. We try to come across empirical reviews and argue within, but couldn't find any clear finding. Thus, the significant effect of category for tax evasion is the pioneer contribution from this paper to the academician and policymakers.

Education: the education level has a positive significant effect on the attitude of tax evasion. The positive result reveals that the higher level of education has the high level of tax evasion attitude will be. The results of the model show respondents who have completed primary education have a more tax evasion attitude than illiterate. The results revealed that the odds in favour of tax evasion attitude increase by a factor of 3.209781 units for those who completed primary education as compared to respondents who have no formal education. This result opposite to the findings of [31] and [11], but supported by Palil, Malek, and Jaguli [32] with the increase of knowledge, people received a good education thought that the odds of being caught were small, which solicit evasion appetite.

Peer: significant positive relationship between peer and tax evasion attitude at $1 \%$ level of significance is resulted from our analysis. The behavior of one tax evader affects other taxpayer and motivates taxpayers not to comply with tax laws and increase evasion tendency. If nearby taxpayers are not paying their tax liability and not detected and penalized, a taxpayer will try to implement their system of exclusion for the tax. The odds ratio implies that the odds ratio in favor of tax evasion attitude increase by 2.291215 units for each unit increase in peer influence on tax evasion concerning other factors held constant.

Tax rate: our analysis results in a positive and statistically significant at $1 \%$ level of significance relationship between tax evasion and tax rate. This indicates increases in the tax rate; increase the attitude of tax evasion. If all other things are held constant, the odds ratio of 1.720723 for tax rate implies, the odds ratio in favour of tax evasion attitude increases by a factor of 1.720723 as the tax rate increase by one unit. This finding is very close to Wei \& Shang [33] which revealed that on average, a $1 \%$ increase in the tax rate results in a $3 \%$ increase in evasion attitude. This relationship is nonlinear: the evasion elasticity is larger at high tax levels. The finding is also consistent with [34-37, 11]. Therefore, this shows statistical evidence to accept the alternative hypothesis stating a tax rate that is perceived as heavy, unfair, and inequitable has a significant contribution to an enhanced positive attitude to tax evasion.

Tax system complexity: a significant positive and relation between tax system complexity and tax evasion attitude at $1 \%$ level of significance in resulted in our analysis. The complexity of the tax system has a statistically significant positive effect on tax evasion attitude at $1 \%$ level of significance. Keeping other factors constant, the odds ratio of 2.339657 for the tax system implies that, the odds ratio in favour of tax evasion increases by a factor of 2.339657 as tax system complexity increase by one unit. In reality, as well, the more the complexity tax system is (especially in terms of time spent to comply and pay tax), the more its noncompliance tendency will be. The significant impact of tax system complexity on tax evasion was also supported by Terzi [34] and Nugnet [38] but they didn't show the direction of the effect of the tax system complexity. In contrary to the current finding, the study of Gambo et al., [39] (revealed as complexity has a negative impact on tax evasion.

This finding is also supported by the world bank [40] Easy of doing Business report of 2020 that Ethiopia is ranked as 132 in paying taxes out of 190 jurisdictions. The paying tax is measured taking variables such as payment, time. Total tax and contribution and rate time for a firm comply as well as post filling process. It also stated that time spent paying tax is $300 \mathrm{hrs}$ per year which is higher 
than the Sub-Saharan average of $280.6 \mathrm{hrs}$. this is the result of system complexity. The same report stated that top-ranking countries are attributed to their establishment of electronic tax filing system compared to their counterparts

Public account: a significant and positive relationship between tax evasion attitude and the role of authorized accountant is identified. This result reveals that there is a positive association between the evasion attitude and the role of authorized accountants. Those taxpayers who have a positive attitude towards evasion also agreed with the instrumental role played by authorized accountants in facilitating evasion the view of the public accountant about tax evasion is ethical sometimes. If all other things are held constant, the odds ratio of 1.014402 for public accountant; the odds ratio in favour tax evasion attitude increases by a factor of 1.014402 as the ethical view of public accountant towards tax evasion increase by one unit.

\section{Conclusion}

Evasion among zone was different due to the difference in the government legitimacy, audit coverage, perception toward corrupt tax official. There is also a significant association between being audited and detection possibility perception of taxpayers which urge for increasing audit frequency by revenue authorities. To our observation of the corruption, score result in relating it to the evasion attitude we have found that there is an inversion relationship. Implying those taxpayers who do have a positive attitude do have a lower corruption score. Based on our understanding, we conclude that Evaders intentionally hide the existing corrupt character of tax officers since they facilitate or willing to facilitate the evasion attempts by taxpayers.

A total of 14 independent variables were considered in the model. Out of these seven of them, Zone, Category of the taxpayer, educational level, peer influence, tax rate, tax system and the role of Authorized accountant were found to be significant at $1 \%, 5 \%$ and $10 \%$ significant level, while the remaining seven variables were not significant in explaining the variations in the dependent variable.

\section{Acknowledgements}

This work is completed with the help of Almighty we believe; so, we are indebted to Thank him. We are Grateful to Dill University for the Grant provided to this research and DU RDO for its unreserved effort in the facilitation during the study. We are grateful for Mr. Yirga Hanbiso SNNPR, Vice Director Law Enforcement Directorate for creating an opportunity for partnership with regional revenue Authority and continues effort to make this study reach this level.

We have received many contributions from so many individuals including our family members and fellow scholars the list may take a thousand pages we are thankful for all that you have done for us May Almighty bless you all.

\section{References}

[1] D. J. Hessin, K. A. Kinsey, H. Elfeers and R. H. Weigel, "Measurement Strategies and Theoretical Models," in Hand Book of Economic Psychology, Dordrecht, Kluwer Academic Publishers, 1988, pp. 517-535.

[2] A. Ghafoor and A. Hannan, "The Determinants of Tax Evasion in Pakistan: A case Study of Southern Punjab," International Journal of Development and Economic Sustainability, vol. 2, no. 4, pp. 50-69, 2014.

[3] J. F. Adebisi and D. O. Gbegi, "Effect of Tax Avoidance and Tax Evasion on Personal Income Tax Administration in Nigeria," American Journal of Humanities and Social Sciences, vol. 1, no. 3, 2013.

[4] M. Mansor and Z. Gurama, "The Determinants of Tax Evasion in Gombe State Nigeria," International Journal of Economics and Financial I, vol. 6, no. 7, pp. 165-170, 2016.

[5] M. Mughal and M. Akram, "easons of tax Avoidance and Tax Evasion: Reflections from Pakistan," Journal of Economics and Behavioural Studies, vol. 4, no. 4, pp. 217-222, 2012.

[6] G. Beckeer, "Crime and punishment: An economic Approach.," Journal of Political Economy, vol. 76, pp. 169$217,1698$.

[7] T. Ritsatos, "Tax evasion and compliance; from the neo classical paradigm to behavioural economics," Journal of Accounting \& Organizational Change, vol. 10, no. 2, pp. 244$262,2014$.

[8] L. Mills and K. Newberry, "The influence of tax and nontax costs on book-tax reporting differences: public and private firms," Journal of American Taxation Association, vol. 23, no. 1, pp. 1-19, 2011.

[9] N. Kiri, "FACTORS AFFECTING TAX EVASION," International Journal of Economics, Commerce and Management, vol. 4, no. 2, 2016.

[10] M. b. Mansor and A. A. Pantamee, "Tax Evasion and Nigeria Tax System," Research Journal of Finance and Accounting, vol. $6,2015$.

[11] G. O. Yalama and E. Gumus, "Determinants of Tax Evasion Behavior: Empirical Evidence from Survey Data," International Business and Management, vol. 6, no. 2, pp. 1523, 2013.

[12] V. J. Hercullas, "Factors influencing tax evasion," University of Pretoria, 2011.

[13] J. H. VENTER, FACTORS INFLUENCING TAX EVASION.

[14] M. Battaglini, L. Guiso, C. Lacava and a. E. Pattacchini, Tax Professionals: Tax-Evasion Facilitators or Information Hubs?, Cambridge: NATIONAL BUREAU OF ECONOMIC RESEARCH, 2019.

[15] P. Sikka and M. P. Hampton, "The role of accountancy firms in tax avoidance: Some evidence and issues," Journal of Accountancy, vol. 29, no. 3, pp. 325-343, 2006.

[16] A. Amina and K. Saniya, "TAX COMPLIANCE AND ITS DETERMINANT THE CASE OF JIMMA ZONE, ETHIOPIA," International Journal of Research In Social Sciences, vol. 6, no. 2, pp. 7-21, 2015. 
[17] D. Endashaw, "Determinants of Tax Evasion in Addis Ababa City Administration: The Case of Bole Sub City Category "A" Taxpayers," UNPUBLISHED, 2019.

[18] CSA, "Population and Housing Census of Ethiopia," Central Statistic, Addis Ababa, 2007.

[19] N. K. Malhotra, Basic Marketing Research: A DecisionMaking Approach, 2, Ed., 2006.

[20] M. L. P. \&. T. A. Saunders, Research Methods for Business Students, 6, Ed., Pearson, 2012.

[21] A. BRYMAN and E. BELL, Business Research Methods, 3rd ed., OXFORD UNIVERSITY PRESS, 2011, p. 187.

[22] T. Yamane, Statistics: An Introductory Analysis, 2, Ed., New York: Harper and Row, 1967.

[23] A. Kumar, Research and writing skills, New York: Lulu press, 2011.

[24] D. W. Lemeshow and S. Hosmer, Applied Logistic Regression, 2 ed., New York: John Wiley \& Sons Inc, 2000.

[25] D. N. Gujarati, Basic Econometrics. 4th edition, New York, USA: The McGraw-Hill Companies, Inc, 2004.

[26] J. Pallant, SPSS SURVIVAL MANUAL: A step by step giude to data analysis using SPSS for widows (Version 10 and 11), Suffolk: Edmundsbury Press Ltd., 2001.

[27] J. E. Fincham, "Response Rates and Responsiveness for Surveys, Standards, and the Journal," American Journal of Pharmaceutical Education, vol. 72, no. 2, pp. 1-3, 2008.

[28] Y. Barch, "Resposne Rate in Academic Studies- A comparative Analysis," Human Relations, vol. 52, no. 4, pp. 421-438, 1999.

[29] D. A. Paul, Logistic Regression Using SAS®: Theory and Application, Second Edition, Cary, NC, USA: SAS Institute Inc, 2012.

[30] W. Green, Econometric analysis of Explanatory Variable, 5th, Ed., New Jersey: Upper Saddle River, 2007.
[31] S. K. Antwi, A. M. Inusah and K. Hamza, "The Effect of Demographic Characteristics of Small and Medium Enterpreneurs on Tax Compliance in the Tamale Metropolis, Hgana," International Journal of Economics, Commerce and Management, vol. 3, no. 3, pp. 1-20, 2015.

[32] M. R. Palil, M. M. Malek and A. R. Jaguli, "Issues, Challenges and Problems with Tax Evasion: The Institutional Factors Approach," Gadjah Mada International Journal of Business, vol. 18, no. 2, pp. 187-206, 2016.

[33] R. F. Wei and J. Shang, "Tax Rate and Tax Evasion: Evidence from the "Missing Imports" in China," Columbia University, Washington,, 2001.

[34] S. Terzić, "Model for determining subjective and objective factors of tax evasion," journal for sustainable development, no. 3, pp. 49-62, 2017.

[35] W. A. K. P. F. Ahmad, "Causes of Tax Evasion in Pakistan: A case study on southern Punjab," International Journal of Accounting and Financial Reporting, vol. 4, no. 2, pp. 273292, October 2014.

[36] A. Lumir, "Determinants of Business Tax Evasion in Transition Economies," StaffordshireUniversity Business School, 2013.

[37] A. Nourzad and S. Crane, "Tax Rates and Tax Evasion; Evidence from Californiya Amnesty Data," National Tax Journal,, vol. 43, no. 2, pp. 189-99, June 1990.

[38] D. A. Nugent, "Legislating Morality: The Effects Of Tax Law Complexity On Taxpayers' Attitudes," The Journal of Applied Business Research, vol. 29, no. 5, pp. 1479-1494, 2013.

[39] E.-M. J. Gambo, A. Mas'ud, M. Nasidi and O. S. Oyewole, "Tax Complexity and Tax Compliance in African Self Assessment Enviroment," International Journal of Management Research \& Revi, vol. 4, no. 5, pp. 575-582, 2014.

[40] World Bank, "Doing Business 2020," International Bank for Reconstruction and Development, Wahington D.C., 2020. 